\title{
Infecciones respiratorias causadas por Mycoplasma Pneumoniae: claves del diagnóstico
}

\author{
* $\quad$ Clyde, W.A. Jr. \\ ** Pacini, D.L. \\ *** Denny, F.W.
}

\section{RESUMEN}

Las infecciones causadas por mycoplasma se caracterizan por instalación insidiosa, malestar general, cefalea, odinofagia, fiebre moderada y tos. Habitualmente ocurren en epidemias intrafamiliares y/o comunitarias que se desarrollan lentamente en el curso de semanas, razón por la cual pasan inadvertidas.

La determinación de crio-aglutininas en muestras pareadas es un examen muy útil. Los autores describen, además, un test simple que se realiza junto al enfermo y que se correlaciona positivamente con el nivel de aglutininas frías.

* Profesor de Pediatría y Microbiología, University of North Carolina at Chapel Hill School of Medicine.

Presidente, International Organization for Mycoplasmology.

* Profesor de Pediatria, Ohio State University College of Medicine, Columbus.

*** Profesor de Pediatria, University of North Carolina.

Reproducido con autorización de: "Diagnosis", Medical Economics Company. Oradell, New Jersey.
Se estima que en Estados Unidos ocurren anualmente 500.000 neumonías y 11.500 .000 casos de tráqueo-bronquitis causadas por mycoplasma pneumoniae. El diagnóstico de estas infecciones se fundamenta en síntomas y signos clínicos estimados característicos, sumados a antecedentes epidemiológicos, más el apoyo de exámenes simples de laboratorio. No hay, sin embargo, ningún examen que permita identificar con certeza y rapidez a este micro-organismo.

\section{CLINICA}

Si bien el mycoplasma pneumoniae causa diversas infecciones respiratorias, existen algunos hechos que son comunes a casi todas ellas y que orientan un diagnóstico precoz.

Estos son:

- Período de incubación prolongado (dos a tres semanas).

- Inicio insidioso y gradual: malestar general, cefalea, odinofagia, fiebre moderada que antecede en varios días a la aparición de tos. La mayoría de los pacientes consulta médico sólo después de una semana o más del inicio de los síntomas. 


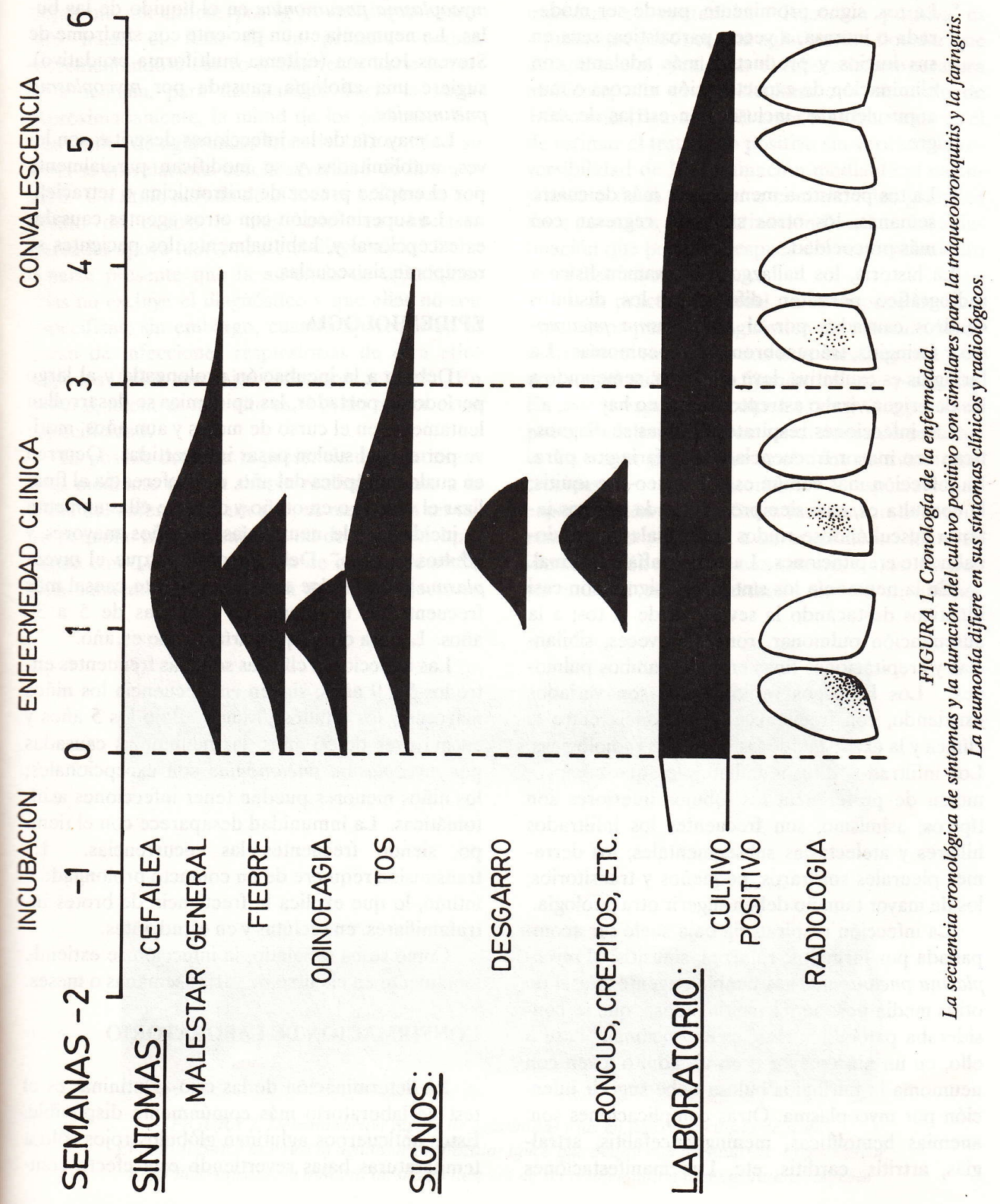


- Desproporción entre la intensidad de las molestias y el cuadro objetivo de infección.

- La tos, signo prominente, puede ser moderada o intensa, a veces, paroxística; seca en sus inicios y productiva más adelante con eliminación de expectoración mucosa o mucopurulenta e, incluso, con estrías de sangre.

- La tos persiste a menudo por más de cuatro semanas; los otros síntomas regresan con más precocidad.

La historia, los hallazgos del examen físico y radiográfico permiten diferenciar los distintos cuadros causados por el Mycoplasma pneumoniae: faringitis, tráqueobronquitis, neumonías. La faringitis es exudativa, leve o intensa, semejando a las de origen viral o estreptocócico; no hay tos.

Las infecciones respiratorias bajas se diagnostican con mayor frecuencia que la faringitis pura. La infección más común es la tráqueo-bronquitis; la consulta es, casi siempre, motivada por tos intensa auscultándose ruidos bronquiales y, ocasionalmente crepitaciones. La radiografía es normal.

En la neumonía los síntomas y signos son casi idénticos destacando la severidad de la tos; a la auscultación pulmonar, roncus, a veces, sibilancias y crepitaciones finas en uno o ambos pulmones. Los hallazgos radiográficos son variados existiendo, con frecuencia, discrepancia entre la clínica y la extensión de las imágenes radiológicas. Los infiltrados difusos unilaterales que comprometen de preferencia los lóbulos inferiores son típicos; asimismo, son frecuentes los infiltrados hiliares y atelectasias subsegmentales; los derrames pleurales son raros, pequeños y transitorios; los de mayor tamaño deben sugerir otra etiología.

La infección respiratoria baja suele ser acompañada por faringitis, rinorrea, sinusitis; el mycoplasma pneumoniae es también agente causal de otitis media pero la miringitis bulosa, que se consideraba patognomónica, es excepcional. Pese a ello, en un niño mayor o en un adulto joven con neumonía la miringitis bulosa debe sugerir infección por mycoplasma. Ótras complicaciones son: anemias hemolíticas, meningoencefalitis, artralgias, artritis, carditis, etc. Las manifestaciones dermatológicas más comunes son las erupciones eritematosas y máculo papulosas en el tronco. En algunos casos de Stevens-Johnson se ha aislado mycoplasma pneumoniae en el líquido de las bulas. La neumonía en un paciente con síndrome de Stevens-Johnson (eritema multiforma exudativo), sugiere una etiología causada por mycoplasma pneumoniae.

La mayoría de las infecciones descritas son leves, autolimitadas y se modifican parcialmente por el empleo precoz de eritromicina o tetraciclina. La superinfección con otros agentes causales es excepcional y, habitualmente, los pacientes se recuperan $\sin$ secuelas.

\section{EPIDEMIOLOGIA}

Debido a la incubación prolongada y al largo período de portador, las epidemias se desarrollan lentamente en el curso de meses y aun años, motivo por el cual suelen pasar inadvertidas. Ocurren en cualquier época del año, de preferencia al finalizar el verano o en otoño y durante ellas aumenta la incidencia de neumonías en niños mayores y adultos jóvenes. Debe recordarse que el mycoplasma pneumoniae es lejos el agente causal más frecuente de neumonía en personas de 5 a 30 años. La tasa de ataque varía de año en año.

Las infecciones clínicas son más frecuentes entre los 5 y 9 años; siguen en frecuencia los niños mayores y los adultos jóvenes. Bajo los 5 años y en mayores de 50 años, las neumonías causadas por mycoplasma pneumoniae son excepcionales; los niños menores pueden tener infecciones asintomáticas. La inmunidad desapareçe con el tiempo, siendo frecuentes las recurrencias. La transmisión requiere de un contacto prolongado e íntimo, lo que explica la frecuencia de brotes intrafamiliares, en reclutas y en estudiantes.

Como se ha señalado, la infección se extiende lentamente en el curso de varias semanas o meses.

\section{CONFIRMACION DE LABORATORIO}

La determinación de las crio-aglutininas es el test de laboratorio más comúnmente disponible. Estos anticuerpos aglutinan glóbulos rojos sólo a temperaturas bajas revertiendo este efecto com- 
pletamente con el recalentamiento. Los adultos sanos pueden tener títulos de hasta 1:20. Las aglutininas frías detectadas en la infección por micoplasma son anticuerpos Ig $\mathrm{M}$ anti-I que aparecen hacia el final de la primera semana incrementándose cuatro o más veces hacia la tercera semana, para desaparecer hacia la sexta. Aproximadamente, la mitad de los pacientes tienen títulos de aglutininas frías de 1:32 o más y su nivel se correlaciona con la severidad de la infección. Un título aislado de al menos 1:128 o su aumento de cuatro o más veces en muestras pareadas apoya fuertemente el diagnóstico. Debe tenerse presente que la ausencia de aglutininas frías no excluye el diagnóstico y que ellas no son específicas; sin embargo, cuando aparecen en el curso de infecciones respiratorias de otra etiología los títulos son bajos (inferiores a 1:128). En general, mientras más alto es el título mayor es su especificidad.

Es posible detectar la presencia de aglutininas frías mediante un test simple realizado junto a la cama del enfermo. Para ello, se mezcla en un tubo pequeño transparente $0,2 \mathrm{ml}$ de sangre del paciente con $0,2 \mathrm{ml}$ de solución de citrato de sodio habitualmente disponible en tubos recolectores de sangre para determinar tiempo de protrombina. Se coloca el tubo en un recolector con hielo durante unos 15 segundos; luego se rota a fin de examinar su contenido. Reacción positiva es aquella que produce una aglutinación flocular que desaparece al recalentar el tubo a la temperatura ambiente, ella se correlaciona con un título de 1:64 o más (figura 2). El error más frecuente es el de estimar el test como positivo sin verificar la reversibilidad de la aglutinación mediante el calentamiento de la muestra o confundir los gránulos finos normales con aglutinación flocular. La aglutinación que persiste después del recalentamiento es un test falso positivo.

En la práctica habitual no se dispone de tests específicos para el diagnóstico de laboratorio de estas infecciones. Los dos más comúnmente usados son el cultivo y la fijación del complemento. En manos expertas el cultivo es muy útil, pero son pocos los laboratorios en condiciones de realizarlo. La mayor positividad se obtiene cultivando secreciones respiratorias, especialmente expectoración (85\%). Otras fuentes son de menor rendimiento y debido a su crecimiento lento su identificación requiere una semana o más. Su mayor utilidad es en enfermos graves o en quienes
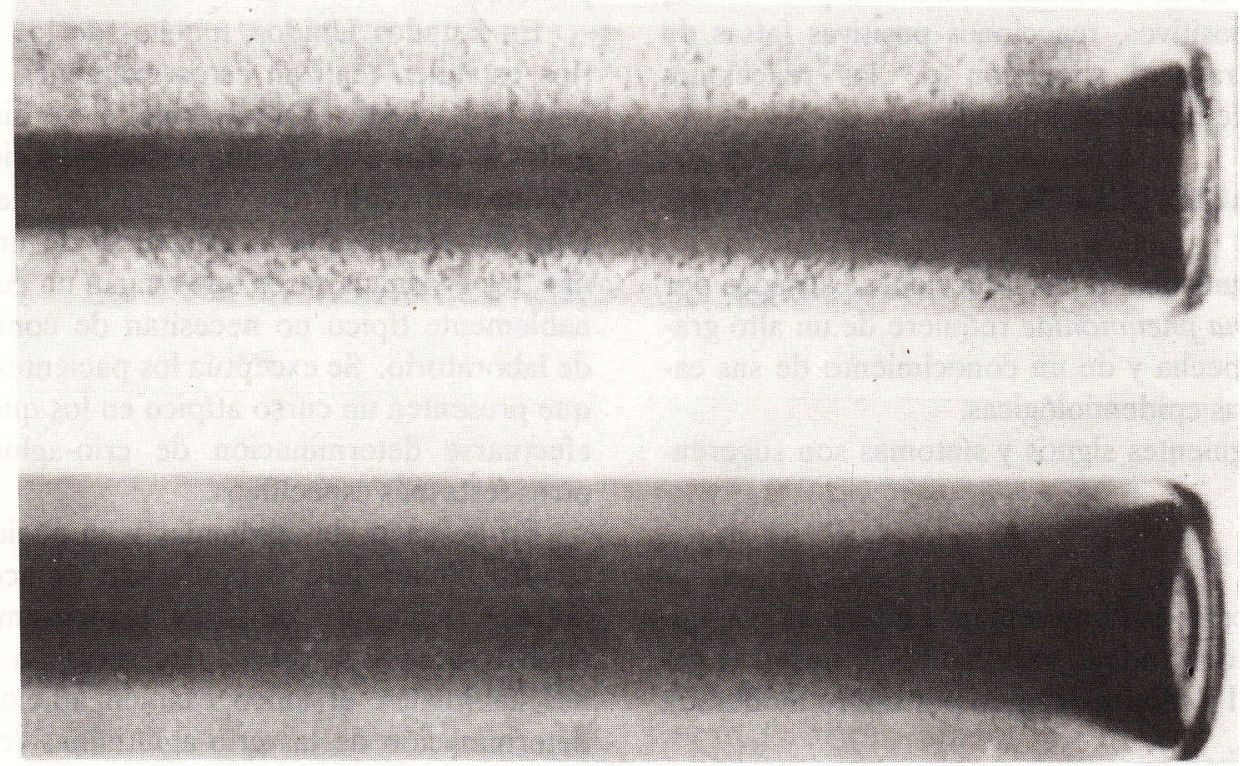

FIGURA 2. Determinación rápida de aglutininas frías en tubo con citrato de sodio.

El tubo superior muestra la aglutinación flocular típica que ocurre con un título de 1:64 o mayor.

En el tubo inferior, la muestra de sangre después de ser recalentada a la temperatura corporal. 
presentan formas clínicas inusuales. Debido a que no hay portadores crónicos, su aislamiento en un individuo enfermo asegura una relación causal.

La fijación del complemento es el método serológico más empleado para determinar niveles de anticuerpos específicos anti-mycoplasma. Sin embargo, debido a que las reinfecciones son frecuentes, la obtención de un título único no es suficiente debiéndose efectuar determinaciones en la fase aguda y en la convalescencia. Se considera positiva una alza que cuadruplique el título inicial. En general, las determinaciones se realizan separadas por 3 a 4 semanas pero, debido al largo período de incubación, las alzas en los títulos de anticuerpos pueden ser evidentes transcurrida una semana.

Otro examen que puede apoyar el diagnóstico es la citología de expectoración: es sugerente una mezcla de neutrófilo y fagocitos mononucleares, acúmulos de células ciliadas desprendidas con pocas o ninguna bacteria. El recuento de leucocitos puede ser normal; en algunas oportunidades, leucocitosis o leucopenia; el incremento de formas inmaduras es excepcional. Por último, hay numerosos hallazgos inmunológicos inespecíficos tales como activación policlonal de linfocitos B, supresión de la inmunidad mediada por células, Coombs positivos, reacciones positivas falsas de sífilis, retraso o supresión de las reacciones cutáneas de hipersensibilidad.

\section{ORIENTACION CLINICA}

El diagnóstico de las infecciones causadas por mycoplasma pneumoniae requiere de un alto grado de sospecha y de un conocimiento de sus características epidemiológicas.

Los siguientes signos y síntomas son sugerentes:

- Enfermedad que semeja a influenza con iniciación gradual, varios días de malestar general y cefalea seguido por fiebre moderada $\mathrm{y}$ tos.

- Molestias respiratorias en desproporción con los signos objetivos de infección.
- Signología respiratoria asociada a miringitis bulosa, síndrome de Stevens-Johnson, artritis, anemia hemolítica.

Las características epidemiológicas sugerentes son:

- Neumonía en pacientes entre 5 y 30 años.

- "Epidemias" compatibles intrafamiliares o comunitarias.

- Neumonías detectadas fuera de la época de las infecciones respiratorias virales.

- Neumonías o tráqueobronquitis en contingentes militares o estudiantes universitarios al finalizar el verano o en otoño.

En general, el diagnóstico del caso individual es más simple si el médico está en conocimiento de una epidemia comunitaria; de ahí la importancia de documentar los casos iniciales, la confirmación serológica de los primeros casos sospechados es, por lo tanto, una medida epidemiológica importante.

En Estados Unidos, muchos de los laboratorios estatales realizan estos exámenes sin costo para el paciente. Obviamente, si se dispone de cultivos, éstos ofrecen una posibilidad cierta y relativamente rápida de confirmación diagnóstica. Una vez establecida la existencia de una epidemia, los próximos casos que tengan un curso razonablemente típico no necesitan de confirmación de laboratorio. Se exceptúa los pacientes graves o que presenten un curso atípico en los que debiera efectuarse determinación de crio-aglutininas $u$ otros tests más específicos.

En ausencia de epidemias y en pacientes con cuadro clínico leve o moderado es aconsejable obtener radiografía de tórax, hemograma, hemocultivos, etc. Si se estima necesario, en condiciones habituales, el único examen adicional es la determinación de las crio-aglutininas realizando, primero, el test rápido descrito que si es claramente positivo no necesita de mayor confirmación. Si es negativo es necesario hacer 
determinaciones de aglutininas frías en muestras pareadas separadas por al menos 5 a 6 días.

En los enfermos más graves o con enfermedad no usual hay que efectuar otros estudios con el propósito de excluir infecciones bacterianas. El hemograma y la citología del desgarro puede proporcionar información útil. Como se ha dicho, la presencia de derrames pleurales importantes obliga a plantear otras etiologías. Aunque los títulos elevados de aglutininas frías sugieren mycoplas$m a$, es necesario realizar, en estos casos, otras determinaciones más específicas. El cultivo de secreciones faríngeas y de desgarro proporciona los más altos rendimientos. Por último, en estos pacientes es, además, útil obtener muestras de suero separadas por 2 a 3 semanas.

\section{BIBLIOGRAFIA}

1. Clyde, W.A. Jr.: Mycoplasma pneumoniae disease symposium: summation and significance. Yale Journal of Biology and Medicine 56 (5,6): 523, 1983.

2. Lyell, A.; Dick, H.; Gordon, A. et al.: Mycoplasma erythema multiforme. Lancet 2:1116, 1967.

3. Clyde, W.A. Jr.: Mycoplasma pneumonia. In: Weinstein, L. and Fields, W.N., eds.: Seminars in infectious disease, vol. 5. Thieme-Stratton, New York, 1983, pp. 81-92.

4. Clyde, W.A. Jr.: Mycoplasma pneumoniae infections of man. In: Barile, M.F., ed.: The Mycoplasmas: Human and animal mycoplasmas, Vol. 2. Academic Press, New York, 1979, pp. 275-306 